\title{
Teaching Hybrid Principles Of Finance To Undergraduate Business Students - Can It Work?
}

Denise Letterman, Robert Morris University

\begin{abstract}
The purpose of this study was to examine the relationship between course design and predictor variables: motivation, satisfaction, and success for students enrolled in the hybrid Principles of Finance course. The participants for this research project were 117 undergraduate students (encompassing 6 semesters) at Robert Morris University, Pittsburgh, Pennsylvania. The results indicate that course design does influence the predictor variables. (A hybrid course combines faceto-face classroom instruction with computer-based learning. These courses move a portion of course learning online and, as a result, reduce the amount of classroom time needed.)
\end{abstract}

Keywords: Hybrid Format, Principles of Finance, Student Performance

\section{INTRODUCTION}

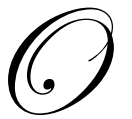

ffering college courses with an online component has allowed universities to reach a wider audience. The variation of online usage can range from completely online (in which there is no face-to-face interaction) to a hybrid course. The definition of a hybrid course is a traditional, face-to-face course that has incorporated online elements. This arrangement of course delivery can appeal to a wide range of instructors and students, even those who are critical of online learning. It can better serve those courses that contain subject material too difficult to teach completely online or solve particular problems associated with courses taught completely online. The hybrid course also provides flexibility for the student requiring them to attend fewer classes rather than two or three times a week.

The experience for both educators and students in a hybrid course vary depending on factors such as course content, course design, student motivation, and student satisfaction. Generalizing about teaching courses containing some online work is as difficult as generalizing about teaching courses face-to-face. For this reason, when designing a hybrid course, failure to consider differences among students learning styles and motivational levels associated with course content can affect a student's ability to succeed or fail in such a course.

Students that register for a hybrid course need to be honest with them. They need to decide whether they will be able to keep motivated and organized enough to succeed especially with the online component of the course. It is important for students to understand that good computer skills are necessary since the focus of a hybrid course is to introduce new knowledge pertaining to the subject.

The purpose of this paper is to determine how course design will influence student performance as determined by changes in motivation, satisfaction, and success in the hybrid Principles of Finance course. In designing the course, it was important to find ways to help keep students motivated and to keep on track with their assignments. It is easy for students to log onto the online component of the course, glance at all the assignments posted and say to themselves, "I'll do them tomorrow; I can catch up". It is also easy for students to say the same thing every day until they reach the end of the semester and find that they have 12 weeks of work due tomorrow. 


\section{REVIEW OF LITERATURE}

Hybrid courses offer a number of advantages over face-to-face teaching and completely online courses. Students are able to have greater flexibility in their schedules while benefiting from face-to-face lecture. Instructors feel the hybrid design allows them to achieve course-learning objectives with greater success than is possible in traditional courses. In addition, faculty have observed greater interaction and contact among students as well as between students and faculty (Garnham and Kaleta, 2002)

However, hybrid courses require students to be able to process written materials and texts at least as efficiently as they process lecture and other discussions (Wolfe, 2000). Students enrolling in a course containing online work need to develop skills beyond those needed to succeed in face-to-face classrooms. Leslie J. Reynolds stresses the need for students to attend 'class' in whatever form that might be, and to be committed to the course regardless of the learning environment to succeed in the course (Reynolds, 2001). Kate Manuel suggests that when designing an online course to keep in mind that many students may be taking such a course for the first time, which can add to greater student frustrations and difficulties. She also found completely online courses to be more difficult to create threaded discussions that equaled face-to-face discussions for students that learn best in a collaborative environment encouraged by direct interaction. These students found the online format to be the most difficult (Manuel, 2001).

For many faculty, moving course material into the online format delivery by using a hybrid system is an attractive alternative (Carroll and Hsu, 2003; Hopper, 2003). However, to transform a part of the course material and assignments online can be difficult, and learning how to convey information effectively in a different medium can be challenging for instructors as well (Lynch, 2002; Smith, 2001).

Planning and designing hybrid courses is a complex task that includes many factors (Pearson and Trinidad, 2005; Trinidad, Aldridge and Fraser, 2005). Factors such as infrastructure, quality of content, peer support networks, and course design may influence the online learning experience (Areti, 2006; Bender, Wood and Vredevoogd, 2004; Trinidad and Pearson, 2004). Other factors to consider include the type of online delivery method, student learning objectives, and reasons why students enroll in the course (Schmidt and Gallegos, 2001). Such factors need consideration when transforming face-to-face courses into hybrid courses for them to be most effective (Lindsay, 2004).

The literature suggests a need for further research pertaining to course design development that enables the most beneficial teaching and learning experience (Thiagarajan and Jacobs, 2001; Trinidad and Pearson, 2004). Learner perceptions and attitudes are paramount in the development and quality of distance education (Areti, 2006; Briggs, 2006; Clayton, 2004). Student feedback pertaining to course design and implementation of the delivery methods provide an essential part of identifying what has been successful in hybrid courses as well as identifying areas in which further improvement is yet needed (Pearson and Trinidad, 2005).

\section{HYBRID PRINCIPLES OF FINANCE COURSE DESIGN}

Students working toward their undergraduate business degree at Robert Morris University (Pittsburgh, PA) are required to take the Principles of Finance course. Because of the pre-requisites for this course (accounting, economics and math), students usually register for the principles course during their junior year. Each semester, the students can choose between the traditional face-to-face format and the hybrid format. The hybrid classes met one hour every week for fourteen weeks during the fall and spring semesters and two hours every week for eight weeks in the summer sessions. The course had a maximum enrollment of 25 students. The class schedule was to cover one chapter each week.

There had been two significant changes to the hybrid Principles of Finance course since first offered in the fall 2005 semester. The first change that occurred summer 2006 separated some course assignments and grades between theory and math components. The second change that took place for the fall 2006 semester was the introduction of the weekly progress report. The design of the course was for the face-to-face portion to focus 
primarily on the math components from each chapter while the online portion focused on both theory and math components. In re-designing the course over the semesters, greater attention to different learning styles of the students was considered. I wanted to take advantage of the particular strengths in learning for all students realizing that some do better on the theory portion of the course while others do better on the math portion. With that in mind, the re-design of the hybrid course was segmented in the following manner.

\section{The Online Component:}

The online component for the Principles of Finance course included the following:

- The course syllabus: The syllabus outlined all assignments and their due dates, the quiz and exam schedule, as well as detailed instructions to complete the online assignments.

- $\quad$ Study sheets for each chapter: The online study sheets included an outline of the lecture, examples of problems solved during the face-to-face sessions, as well as answers to assigned homework problems.

- Extra chapter problems: In addition to specific homework assignments, students were required to solve extra problems for each chapter. Students were to post their solutions to these problems in the 'assignment' section of Blackboard. Several students took this as an opportunity to ask questions about problems they did not understand. It also provided a way for me to correct individual student's work. The online assignments represented $20 \%$ of a student's grade. Grading was based on the completeness of the work by the due date and not necessarily on the correctness of the work.

- Threaded questions for each chapter: A question pertaining to application of the theory was posted as a threaded question in which all students could view and respond. Students were not required to respond but those that did received bonus points at the end of the semester. (Bonus points are extra points added to student's weighted average and could add as much as $7 \%$ to a grade.)

- $\quad$ Student's progress report: Each week, students were to turn in a progress report that served as a reminder of student course goals, what assignments were due for the week, if they completed the previous week's assignments, and the level of satisfaction of their work. The forms were a part of the bonus points. (Refer to Table 1.)

\section{The Face-To-Face Component:}

The face-to-face component for the Principles of Finance course included the following:

- $\quad$ Problem solving: Class time was spent solving the math problems found on the chapter study sheets. If time permitted, major theory points were reviewed in addition to addressing homework questions students may have had.

- Weekly quizzes: Quizzes that focused only on theory concepts from each chapter were scheduled each week with the exception of weeks exams were scheduled. The lowest quiz grade was dropped and the remainder represented $20 \%$ of the student's grade.

- Exams: There were three exams during the semester that combined the theory concepts with the math. The exams represented $60 \%$ of the student's grade.

\section{HYPOTHESIS}

Based on the literature review, it is suggested that course design, especially in a hybrid course, can affect student performance in areas of motivation, satisfaction, and success. As a result, the purpose of this paper was to determine if students enrolled in the hybrid Principles of Finance course demonstrated a different level of motivation, satisfaction, and success than students enrolled in the courses following the two significant changes in course design. To test this research hypothesis, the following null hypotheses were used:

H1: Semesters that separated some course assignments and grades between theory and math components did not show increased student performance than semesters that did not separate theory from math for the same assignments and grades. 
H2: Semesters using the weekly progress report did not show an increase in student performance than semesters that did not use the progress report.

Based on prior literature, the two hypotheses are expected to be rejected.

\section{DATA COLLECTION}

Data collected by means of a questionnaire expanded over the past 6 semesters. Each student from the hybrid Principles of Finance course received a questionnaire on the final day of class. The anticipated completion time for the questionnaire was ten to twelve minutes. The questionnaire was constructed to give the students limited alternative responses to each question. The purpose of the questionnaire was to analyze how changes in course design affected student motivation, satisfaction, and success. There were 131 questionnaires handed out in which 14 were not usable because the questionnaire was not completed. The questionnaires were kept completely anonymous to eliminate any bias that may occur if the respondents were to identify themselves.

A sample of the questions used in the study is available in Tables 2 through 4 . The results were coded using standard coding procedures with modified Likert scales for questions related to student motivation and satisfaction. Descriptive statistic results from the study were determined using SPSS.

The demographic analysis of the questionnaire revealed the following characteristics:

- $\quad$ Males comprised $46.8 \%$ of the respondents and females $53.2 \%$ of the respondents.

- $\quad$ Of the respondents, $5.4 \%$ were sophomores, $56.9 \%$ were juniors, and $37.7 \%$ were seniors.

- Students majoring in finance, accounting or economics represented $46.8 \%$ of the respondents and $53.2 \%$ of the respondents majored in marketing or management (including all variation).

- $\quad$ Four age groups identified in the study included: 18 to 21 years old (8.1\%); 22 to 25 years old (37.8\%); 26 to 29 years old $(26.2 \%)$; and over 29 years old $(27.9 \%)$.

- Employment status indicated that $44.1 \%$ of the students worked 40 hours or more a week; $8.1 \%$ worked between 30 and 39 hours a week; 16.2\% indicated working between 20 and 29 hours a week; 19.9\% worked between 10 to 19 hours a week; $7.2 \%$ worked between 1 and 9 hours each week; and $4.5 \%$ did not work at all.

- $\quad$ Of the respondents, $45.2 \%$ had never taken a hybrid course prior to taking the hybrid Principles of Finance course while $54.8 \%$ indicated they had previously taken a hybrid course.

\section{VARIABLES IN THE ANALYSIS}

The three dependent variables identified for the study are motivation, satisfaction and success. Tables 2 through 4 indicate questions from the questionnaire used to analyze student performance under the two hypotheses along with student mean responses to each question. Factors that analyzed student success included all graded components for the course, bonus points earned by the students over the semester, and the retention rate.

\section{RESULTS}

\section{General Questions}

Some questions on the questionnaire were designed to gather general information pertaining to the hybrid format for the Principles of Finance course. Table 4 outlines these questions and shows student mean responses to them.

Overall, students liked the flexibility provided by a hybrid course. However, they initially felt that less work would be required since there were fewer classes. Those that did not take a hybrid course before did not realize that they would be responsible for most of the learning. 
Students found the study sheets, which outlined the chapters and provided in-class examples, to be very helpful in explaining major concepts for each chapter. Having class examples on the study sheet eliminated the need for students to spend class time copying the problems, which in turn permitted more class time to focus on the solutions and theory necessary to solve each problem.

With limited class time, reviewing homework problems often was not permitted. Having the answers to these problems on the study sheets allowed students to identify which problems they could not correctly solve. Email correspondence was utilized to address student questions pertaining to homework problems.

Most students liked the hybrid format, but indicated a stronger likeness of the hybrid format after the two major changes in course design. The hybrid course was set-up in such a way that students had several avenues to ask questions pertaining to course material and many of them took advantage of this.

The instructions for the online work were given through several sources including the syllabus, announcements posted on Blackboard, student e-mail accounts, and in the assignments. Since 45 percent of the students had indicated never taking a hybrid course before, articulating instructions is the first step for students to succeed in a hybrid course.

\section{H1: Motivation (Refer to Table 2)}

Separation between theory and math components occurred after spring 2006's semester. Because of the change, online assignments included only math problems while quizzes and threaded discussions were based only on theory. Students had indicated that they were more likely to review in-class math examples more frequently as well as having a greater understanding of math concepts then semesters that combined theory and math for online assignments.

By isolating some assignments to math, I was hoping to find more students completing their homework assignments when due. However, based on student responses, there was no change in homework completion. This was supported by a low number of students who handed in homework when periodically collected unannounced over the semester.

The threaded question format was based on theory questions with no change to this format. The purpose of the threads was to encourage discussion on key topics in each chapter and had benefited students over the semesters.

Weekly quizzes were always given in the hybrid class but after the spring 2006 semester, quizzes focused only on theory concepts from each chapter. Because of the change, students indicated a stronger agreement that quizzes encouraged them to review theory more often and helped them understand theory better for exams. completion.

The study showed course re-design did increase student motivation with the exception of homework

\section{H1: Satisfaction (Refer to Table 2)}

Students taking the hybrid course liked the convenience and freedom to work from home and at their own pace. However, with fewer class meetings it was easy for students to procrastinate, miss assignments, and fall behind. To prevent this from happening, weekly quizzes were given in the hybrid principles course to help students keep up with reading assignments. To help students focus on theory concepts, quizzes contained question on theory only starting in the summer 2006 semester. Based on student responses to the questionnaire, this change helped students be better prepared for the theory portion of exams then when quizzes contained both theory and math components. 
During the same semester, online assignments that once contained questions pertaining to both theory and math components from each chapter were changed to include only math problems. Again, students felt this change allowed better understanding of the math component of the course.

Overall, students did indicate increased satisfaction in the hybrid course when some assignments and grades dealt only with theory concepts while others dealt only with math concepts.

The only area of the study that showed no increase in student performance pertained to students asking for help if they were not able to complete the homework assignments correctly. (e.g. Students did not get the same answer to the problems as shown on the study sheets.) With no increase in the number of students completing homework assignment, the number of questions pertaining to homework assignment did not change.

\section{H2: Motivation and Satisfaction (Refer to Table 3)}

In designing a hybrid course, it is important to have weekly assignments and constant reminders of them to encourage students not to procrastinate and fall behind.

The design of the weekly progress report was to provide a constant reminder of assignments and their due dates. It was first used during the fall 2006 semester. The purpose was not only to remind students of their weekly assignments but for them to list their goal for the week. Questions pertaining to weekly assignments and student's level of satisfaction of their work were asked. Responses were based on a 4-point scale. (Refer to Table 1)

The final section of the weekly progress report reminded students of different ways to earn bonus points (maximum of 7 percentage points added to a student's final grade) and what each student did during the week to earn the points. "Had homework ready in case it was collected" was one of the ways students were able to earn bonus points. Approximately 47 percent of the students indicated having homework completed. Of those, only 1.5 percent indicated having homework completed on the weekly progress report but did not turn homework in when collected unannounced.

Based on questionnaire responses, the weekly progress report did motivate students to keep up with class assignments. Students indicated that they were less likely to fall behind in the hybrid class because the report reminded them when assignments were due.

Student responses indicated that the weekly progress report helped them achieve their weekly goals as well as their course goals. The level of satisfaction of assignments improved over the semester as indicated on the report. Again, the one area that showed no improvement in satisfaction was completion of homework problems. Although homework was due every week, a small percentage $(17$ percent) of the students indicated that homework assignments were not due the previous week. Another 36 percent indicated not having completed homework assignments and were not satisfied with their work.

Overall, student performance did increase with the use of the weekly progress report with the exception of completion and satisfaction of homework assignments which did not change over the semester..

\section{Success}

To be successful, a hybrid course required careful pedagogical re-design from the traditional face-to-face method of teaching. Considering course learning objectives and student learning styles, it is necessary to determine which assignments are better achieved online and which are best covered in the face-to-face sessions. Student retention, grated assignments and bonus points accumulated during the semester were used to measure this portion of student performance.

The two hypotheses stated that changes to course design would not lead to greater student performance in a hybrid course. To observe any change in success, a comparison was made in average exam grades over the six 
semesters for the hybrid course. In addition, a comparison of average exam grades was made to the traditional faceto-face Principles of Finance course taught during the same semester. After the re-design of the hybrid course, the average exam grades for the hybrid course improved over the semesters and were higher than the traditional course.

Since quizzes were not given in the traditional face-to-face course, comparison of average quiz scores was limited to the hybrid class over the semesters. The study showed that quiz grades were higher after the course was re-designed which lead to higher exam grades

After the re-design of the course, there was a higher retention rate in my hybrid class than seen in previous semesters. The retention rate was also higher in the hybrid class than seen in the traditional face-to-face principles class for the same semester. A study conducted by The University of Central Florida in 2001 showed student retention in hybrid courses to be better than retention in courses taught completely online and equivalent to that of face-to-face courses. (Dziuban, Hartmanh, Moskal, Sorg, and Truman-Davis, 2001)

The threaded questions were related to student discussions used in the traditional face-to-face class. The results found that more students participated in the online discussion of the threaded questions that students responding to the same question asked in the traditional class. This lead to a greater allocation of bonus points to students in the hybrid class.

The results of the study showed an increase in success for students enrolled in the hybrid course after the course re-design.

\section{CONCLUSION}

To be successful, a hybrid course requires careful pedagogical re-design from the traditional face-to-face format. The focal points for the re-designed Principles of Finance course are course goals and objectives, maintaining student motivation, deciding which assignments are best achieved online and which are best left for the face-to-face sessions, student satisfaction, and student success. Assignments that take advantage of different learning styles of students will lead to achieving course goals and objectives.

The Principles of Finance course is a difficult course for students. When offered in the hybrid format, students need to be more committed to the course in order to succeed. They need frequent reminders of what their course goals are and when assignments are due. Providing an avenue for students to reflect on their level of satisfaction pertaining to their course work helped to remind students that more effort was required to succeed in a hybrid course.

The results from the study for the most part support the research hypotheses in that students enrolled in the hybrid Principles of Finance course demonstrated a different level of motivation, satisfaction and success than students enrolled in the course after the re-design. The use of the weekly progress reports and the isolation of assignments that concentrated on theory concepts and those that concentrated on the math concepts did increase motivation, satisfaction and success for students enrolled in the hybrid course after the re-design.

\section{REFERENCES}

1. Areti, V. (2006). Satisfying Distance Education Students of the Hellenic Open University. E-mentor, 2 (14), 1-12.

2. Bender, D. M., Wood, B. J., and Vredevoogd, J. D. (2004). Teaching Time: Distance Education Versus Classroom Instruction. The American Journal of Distance Education, 18(2), 103-114.

3. Briggs. M. J. G. (2006). Comparison of Student Perceptions of Classroom Instruction: Traditional, Hybrid, and Distance Education. Turkish Online Journal of Distance Education (TOJDE), 7(2), 46-51.

4. Carroll, Brenda and Hsu, Lily. (2003). Going Hybrid: Online Course Components Increase Flexibility of On-Campus Courses. Online Classroom, February. 
5. Clayton, J. (2004). Investigating Online Learning Environments. In R. Atkinson, C. McBeath, D. JonasDwyer, R. Phillips, (Eds.), Beyond the Comfort Zone: Proceedings of the $21^{\text {st }}$ ASCILITE Conference (p197-200). Perth, Australia: Australasian Society for Computers in Learning in Tertiary Education.

6. Dziuban, C. D., Hartman, J. L., Moskal, P. D., Sorg, S. E., and Truman-Davis, B. (2001). The Payoff for Systemic Evaluation of University-Wide Distributed Learning. http://Pegasus.cc.ucf.edu/ rite/Presentations/NLII\%202001.pt. Retrieved May 2007.

7. Garnham, Carla, and Kaleta, Robert. (2002) Introduction to Hybrid Courses http://www.uwsa.edu/tt/articles/garnham.htm. Retrieved July 9, 2007

8. Hopper, Keith. (2003). Reasons to Go Hybrid. Distance Education Report 7(24), 7.

9. Lynch, Margarita McVay. (2002). The Online Educator. New York: Routledge.

10. Manuel, Kate. (2001). Teaching an Online Information Literacy Course. Reference Services Review 29(3), 219-228.

11. Pearson, J., and Trinidad, S. (2005). OLES: An Instrument for Refining the Design of e-Learning Environments. Journal of Computer Assisted Learning, 21, 396-404.

12. Reynolds, Leslie J. (2001). Model for a Web-Based Information Literacy Course: Design, Conversion, and Experiences. Science and Technology Libraries 19. 3/4, 165-178.

13. Schmidt, E. K.., and Gallegos, A. (2001). Distance Learning: Issues and Concerns of Distance Learners. Journal of Industrial Technology, 17(3), 2-5.

14. Smith, Susan Sharpless. (2001). Web-Based Instruction. Chicago: American Library Association.

15. Thiagarajan, G. and Jacobs, C. (2001). Teaching Undergraduate Mechanics via Distance Learning: A New Experience. Journal of Engineering Education, 1, 151-156.

16. Trinidad, S., Aldridge, J., and Fraser, B. (2005). Development, Validation and Use of the Online Learning Environment Survey. Australasian Journal of Educational Technology, 21 (1), 60-81.

17. Trinidad, S., and Pearson, J. (2004). Implementing and Evaluating e-Learning Environments. In R. Atkinson, C. McBeath, D. Jonas-Dwyer, R. Phillips, (Eds.), Beyond the Comfort Zone: Proceedings of the $21^{\text {st }}$ ASCILITE Conference (p 895-903). Perth, Australia: Australasian Society for Computers in Learning in Tertiary Education.

18. Wolfe, Christopher R. (2000). Learning and Teaching on the World Wide Web in Learning and Teaching on the World Wide Web. San Diego: Academic Press, 1-2. 
Table 1: Weekly Progress Report

\title{
HYBRID PRINCIPLES OF FINANCE \\ WEEKLY PROGRESS REPORT
}

Student's Name:

Semester:

Week of: (Show date)

Tasks due $\underline{\underline{\text { THIS }}}$ week

Goal for $\underline{\underline{T H I S}}$ week:

Use the following scale to rate each assignment listed below:

Level of completion for tasks due LAST week:

$1=$ The assignment was not due this week

$2=\mathrm{I}$ did not do the assignment this week

$3=$ I completed part of the assignment

$4=$ I completed the entire assignment

How satisfied were you with LAST week's assignment:

$1=$ The assignment was not due last week

$2=$ I was not very satisfied with my work

$3=$ I was somewhat satisfied with my work

$4=$ I was very satisfied with my work

\author{
Weekly assignment: \\ 1. Reading the chapter \\ 2. Reviewing the study sheets \\ 3. Homework problems \\ 4. Extra problems (journal entries) \\ 5. Threaded question response \\ 6. Quizzes \\ 7. Exams
}

Completion Level

$\begin{array}{llll}1 & 2 & 3 & 4 \\ 1 & 2 & 3 & 4 \\ 1 & 2 & 3 & 4 \\ 1 & 2 & 3 & 4 \\ 1 & 2 & 3 & 4 \\ 1 & 2 & 3 & 4 \\ 1 & 2 & 3 & 4\end{array}$

$\underline{\text { Satisfaction Level }}$

What efforts did you take $\underline{\underline{\text { LAST }}}$ week to accumulate bonus points?

1. E-mailed questions to the instructor

2. Asked questions during class

3. Had homework ready in case it was collected

4. Responded to the threaded discussion

5. Attended class

6. Office visit

$\begin{array}{cc}\text { Yes } & \text { No } \\ \text { Yes } & \text { No } \\ \text { Yes } & \text { No } \\ \text { Yes } & \text { No } \\ \text { Yes } & \text { No } \\ \text { Yes } & \text { No }\end{array}$


Table 2: Course re-design for $\mathrm{H1}$

\section{Sample Questions Taken From the Questionnaire - Motivation}

Q8: The online assignments encouraged me to review in-class math examples more frequently.

Q9: Participating in and reviewing threaded questions helped me better understand the theory.

Q10: The weekly quizzes encouraged me to review the theory more frequently.

Q13: Online assignments encouraged me to complete my homework problems when due.

\begin{tabular}{|c|c|c|c|c|c|}
\hline \multicolumn{6}{|c|}{ Mean Questionnaire Response's By Semester } \\
\hline$\underline{\text { Fall '05 }}$ & Spring '06 & $\underline{\text { Summer '06 }}$ & $\underline{\text { Fall '06 }}$ & $\underline{\text { Spring '07 }}$ & $\underline{\text { Summer '07 }}$ \\
\hline 2.2 & 2.5 & 3.2 & 3.9 & 4.3 & 4.1 \\
\hline 3.1 & 3.5 & 2.9 & 3.4 & 3.8 & 3.3 \\
\hline 2.6 & 2.5 & 2.9 & 3.2 & 3.5 & 4.1 \\
\hline 2.1 & 2.6 & 2.8 & 2.5 & 2.1 & 2.3 \\
\hline
\end{tabular}

Q11: Quizzes helped me better understand theory for exams.

Q12: Online assignments helped me better understand the math portion of the course.

Q15: I asked for help if I did not get the same answers for homework problems found on the study sheets.

Q18: I liked having part of my grade based only on theory.

Q19: I like having part of my grade based only on math problems.

\begin{tabular}{|c|c|c|c|c|c|c|}
\hline & \multicolumn{6}{|c|}{ Mean Questionnaire Response's By Semester } \\
\hline & $\underline{\text { Fall ’05 }}$ & Spring '06 & Summer'06 & Fall '06 & Spring '07 & $\underline{\text { Summer '07 }}$ \\
\hline Q11 & 2.9 & 3.1 & 4.2 & 3.9 & 3.3 & 3.7 \\
\hline Q12 & 3.1 & 2.7 & 4.0 & 3.7 & 4.2 & 4.2 \\
\hline Q15 & 2.1 & 2.5 & 2.4 & 2.1 & 2.8 & 2.8 \\
\hline Q18 & --- & --- & 4.3 & 4.1 & 3.9 & 4.3 \\
\hline Q19 & --- & --- & 3.8 & 3.6 & 4.1 & 3.9 \\
\hline
\end{tabular}

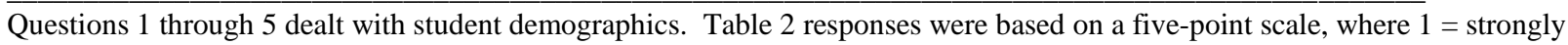
disagree, 2 = disagree, $3=$ not sure, $4=$ agree, and $5=$ strongly agree. Dashed entries indicate semesters that the question did not appear on the questionnaire. 
Table 3: Course re-design for $\mathrm{H} 2$

\section{Sample Questions Taken From the Questionnaire - Motivation}

Q6: The weekly progress reports helped me keep up with class assignments.

Q22: The weekly progress reports encouraged me not to fall behind on assignments.

\begin{tabular}{|c|c|c|c|c|c|}
\hline \multicolumn{6}{|c|}{ Mean Questionnaire Response's By Semester } \\
\hline$\underline{\text { Fall '05 }}$ & $\underline{\text { Spring '06 }}$ & $\underline{\text { Summer '06 }}$ & $\underline{\text { Fall } ’ 06}$ & $\underline{\text { Spring '07 }}$ & $\underline{\text { Summer '07 }}$ \\
\hline--- & --- & --- & 3.9 & 4.2 & 4.3 \\
\hline --- & --- & --- & 3.6 & 4.2 & 4.0 \\
\hline
\end{tabular}

Sample Questions Taken From the Questionnaire - Satisfaction

Q14: The weekly progress reports helped me achieve my course goal.

Q23: The weekly progress reports helped me meet my course goal.

$\begin{array}{lllll}\text { Fall '05 } & \underline{\text { Spring '06 }} & \begin{array}{c}\text { Mean Questionnaire Response's By Semester } \\ \text { Summer'06 }\end{array} \quad \underline{\text { Fall '06 }} \quad \underline{\text { Spring '07 }} \quad \underline{\text { Summer '07 }}\end{array}$

$\begin{array}{lllllll}\text { Q14 } & --- & --- & -- & 3.1 & 3.3 & 3.0 \\ \text { Q23 } & --- & --- & --- & 3.0 & 3.3 & 3.8\end{array}$

Table 3 responses were based on a five-point scale, where $1=$ strongly disagree, $2=$ disagree, $3=$ not sure, $4=$ agree, and $5=$ strongly agree. Dashed entries indicate semesters that the question did not appear on the questionnaire.

Table 4: General Questions Pertaining to the Hybrid Principles of Finance Course

\begin{tabular}{|c|c|c|c|c|c|c|}
\hline \multicolumn{7}{|c|}{ Sample Questions Taken From the Questionnaire } \\
\hline Q7: & \multicolumn{6}{|c|}{ The chapter study sheets were helpful in keeping up with reading assignments. } \\
\hline Q16: & \multicolumn{6}{|c|}{ I liked the hybrid (combining face-to-face lecture with online work) format of the course. } \\
\hline Q17: & \multicolumn{6}{|c|}{ I liked having different ways to ask the instructor questions (e-mail, online assignments, and office hours). } \\
\hline Q20: & \multicolumn{6}{|c|}{ The instructions for the online work were easy to follow. } \\
\hline Q21: & \multicolumn{6}{|c|}{ Completing online assignments was more difficult than expected. } \\
\hline Q24: & \multicolumn{6}{|c|}{ The flexibility of the hybrid course was beneficial. } \\
\hline Q26: & \multirow{2}{*}{\multicolumn{6}{|c|}{ I thought less work would be required in the hybrid course since there were fewer class sessions. }} \\
\hline Q27: & \multicolumn{4}{|c|}{ Overall, how satisfied were you with the hybrid course? } & & \\
\hline \multicolumn{7}{|c|}{ Mean Questionnaire Response's By Semester } \\
\hline & $\underline{\text { Fall '05 }}$ & $\underline{\text { Spring '06 }}$ & $\underline{\text { Summer'06 }}$ & $\underline{\text { Fall '06 }}$ & Spring '07 & $\underline{\text { Summer '07 }}$ \\
\hline Q7 & 3.7 & 3.5 & 3.8 & 3.8 & 4.0 & 3.9 \\
\hline Q16 & 3.2 & 3.9 & 3.7 & 4.2 & 4.3 & 4.6 \\
\hline Q17 & 3.1 & 3.8 & 2.8 & 3.8 & 3.0 & 4.2 \\
\hline Q20 & 2.8 & 3.0 & 2.6 & 3.3 & 3.6 & 3.9 \\
\hline Q21 & 4.3 & 4.1 & 4.0 & 3.6 & 3.8 & 3.1 \\
\hline Q24 & 4.3 & 4.4 & 3.9 & 4.8 & 3.9 & 4.2 \\
\hline Q26: & 3.5 & 3.8 & 3.5 & 4.3 & 4.0 & 3.9 \\
\hline Q27 & 2.4 & 2.9 & 3.1 & 3.8 & 4.1 & 4.4 \\
\hline
\end{tabular}


NOTES 